\title{
Synthesis and Characterization of Co (II), Ni (II) and Cu (II) Complexes With Ethyl - $\alpha$ - Isonitrosoacetoacetate(HEINA)
}

\author{
A.K. TAKSANDE ${ }^{1}$, R. D. RAUT ${ }^{2}$ M. D.CHOUDHARY ${ }^{3}$ and N.N. BHOLE ${ }^{4}$ \\ ${ }^{1}$ (S.D.College of Engineering, wardha,India) \\ 2 (J.B.College of Science, Wardha.,India) \\ ${ }^{3,4}$ (B.D.College of Engineering, Sewagram, Wardha.,India)
}

\begin{abstract}
Ethyl-a-Isonitrosoacetoacetate has been prepared by reacting Ethyl acetoacetate and sodium nitrite. $\mathrm{Co}$ (II), $\mathrm{Ni}$ (II) and $\mathrm{Cu}$ (II) Complexes have been prepared by reacting metal acetate with this ligand Ethyl- $\alpha$ Isonitrosoacetoacetate. All these complexes are dark in colour. They have been characterized by elemental analysis, magnetic measurements and spectral studies. The complexes were found to have composition $M L_{2}$, where $L=$ Ethyl- $\alpha$-Isonitrosoacetoacetate and $M=C u$ (II), Ni (II) and Co (II). On the basis of elemental and spectral studies six coordinated octahedral geometry assign for Co (II), Ni (II) and square plane for Cu (II) complexes.
\end{abstract}

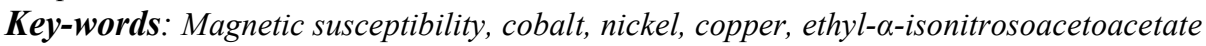

\section{Introduction}

There is great interest in synthesis and characterization of coordination compounds. This is because the coordinated ligand are biologically more active than the uncoordinated one. ${ }^{1}$ The Co (II) complex of 2- acetyloxybenzoic acid (aspirin), a ligand used an analgesic is reported to be more significantly active as an anti- inflammatory agent than the uncoordinated one. ${ }^{2}$ Coordinating ability of isonitroacetophenon and its derivatives with transition element ${ }^{3-6}$, alkali meta ${ }^{7-9}$ and alkaline earth metal ${ }^{10}$. On coordination the biological activity of mixed ligand metal complexes of ethyl- $\alpha$-isonitosoacetoacetate changes markedly. In view of these interesting properties of ligand metal complexes, synthesis and characterization of $\mathrm{Co}$ (II), $\mathrm{Ni}$ (II) and $\mathrm{Cu}$ (II) of ethyl- $\alpha$ - isonitosoacetoacetate are reported.

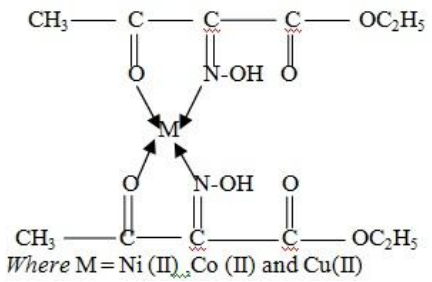

\section{Experimental}

All the chemicals used were of analytical grade.

\subsection{Preparation of Ligand}

Ethyl acetoacetate 1.4 moles and 3.5 mole of glacial acetic acid were taken in three naked round bottom flask fitted with thermometer, reflux condenser and mechanical stirrer and cooled in ice bath at $0^{0} \mathrm{C}$ and a solution of $95 \%$ sodium nitrite was added over a period of one hour and temperature being kept between $5^{0} \mathrm{C}$ to $10^{\circ} \mathrm{C}$. This mixture mixed with double distilled water and stirring for two hour and extracted with ether. After drying ether solution with sodium sulphate the solvent was distilled off on a steam bath the crude product was dissolved in toluene and cooled to $-13^{\circ} \mathrm{C}$ to $-15^{\circ} \mathrm{C}$. The separated white crystals were filtered, washed and analyzed.

\subsection{Preparation of complexes}

A warm ethanolic solution of metal acetate $(0.01 \mathrm{~m})$ was added to ethanolic solution of ligand $(0.02 \mathrm{~m})$. The resulting solution was refluxed for about six hours. The complex thus formed was filtered, washed with alcohol and dried at $110^{\circ} \mathrm{C}$ for 4 to 6 hours. Re-crystallized from chloroform and analyzed for Carbon, Hydrogen, and Nitrogen.

\section{Result and Discussion}

The metal estimation was carried out by standard method and nitrogen by kjeldahl method. The conductance was measured in DMF and DMSO solvent on and Elico CM-82 Conductivity Bridge. The 
Synthesis And Characterization Of Co (II), NI (II) And Cu (II) Complexes With Ethyl -Amagnetic susceptibility measurement at room temperature was made on Gouy's balance. The IR spectra were recorded on Perkin-Elmer-137 instrument in Nujol mull/KBr pellets. The elemental analysis shown in table-1 indicates that all the metal complexes have 1:2 stoichiometry and are dark in colour, soluble in DMF and DMSO. The molar conductance values obtained for these complexes at the concentration of $10^{-4}$ is in the range

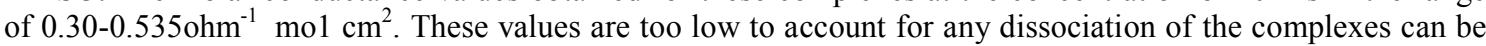
regarded as non-electrolyte. The magnetic moment values for $\mathrm{Cu}$ (II) complexes are in the range of $5.05-5.14$ $\mathrm{BM}$ Indicating that the $\mathrm{Cu}$ (II) complexes are typically high spin complexes and having square planer structure. The Ni (II) complexes were found to diamagnetic indicating octahedral coordination of ligands around $\mathrm{Ni}$ (II) ion. The CO (II) complexes exhibit magnetic moment in the range of 2.34-2.95 BM suggestive of octahedral nature for these complexes. HEINA shows a broad band around $3400 \mathrm{~cm}^{-1}$ is assigned to the hydrogen bonded $\mathrm{OH}$ stretching this assignment is further confirming by the presence of new bond at $2460 \mathrm{~cm}^{-1}$. HEINA reveals two peaks at $1760 \mathrm{~cm}^{-1}$ and $1745 \mathrm{~cm}^{-1}$ which may be attributed to the ester $\mathrm{C}=\mathrm{O}$ and Ketone $\mathrm{C}=\mathrm{O}$ respectively. The band near $1640 \mathrm{~cm}^{-1}$ may be assign to the $\mathrm{C}=\mathrm{N}$ stretching frequency which is usually appeared in the spectra of oxime in the range $1685-1650 \mathrm{~cm}^{-1}$. The peak $1470 \mathrm{~cm}^{-1}$ may possible be due to $\mathrm{CH}_{2}$. The asymmetric and symmetric bending modes of $\mathrm{CH}_{3}$ overlap with bands at $1458 \mathrm{~cm}^{-1}$ and $1378 \mathrm{~cm}^{-1}$ respectively. Stretching band and $\mathrm{COOC}_{2} \mathrm{H}_{5}$ group at $1268 \mathrm{~cm}^{-1}$ and $1078 \mathrm{~cm}^{-1}$.

The N-O frequency in simple oxime appears between $930-960 \mathrm{~cm}^{-1}$ in the peak near $1168 \mathrm{~cm}^{-1}$ and $950 \mathrm{~cm}^{-1}$ in HEINA may therefore attributed to $\mathrm{N}-\mathrm{O}$ stretching mode ${ }^{11}$.

Table-1: Elemental Analysis and Magnetic Moment of the Complexes

\begin{tabular}{|c|c|c|c|c|c|c|c|}
\hline Compounds & $\% \mathrm{C}$ & $\% \mathrm{H}$ & $\% \mathrm{~N}$ & \%Metal & $\mu$ & $\begin{array}{c}\text { Molar } \\
\text { Conductance }\end{array}$ & Concentration \\
\hline HEINA & $\begin{array}{l}45.30 \\
45.28\end{array}$ & $\begin{array}{l}5.60 \\
5.70\end{array}$ & $\begin{array}{l}5.80 \\
8.80\end{array}$ & ---- & ---- & ---- & ---- \\
\hline $\mathrm{Cu}(\mathrm{EINA})_{2}$ & $\begin{array}{c}37.74 \\
(37.64)\end{array}$ & $\begin{array}{c}4.77 \\
(4.81)\end{array}$ & $\begin{array}{c}7.33 \\
(7.40)\end{array}$ & $\begin{array}{l}16.65 \\
(16.1)\end{array}$ & 0.95 & 0.520 & $1.25 \times 10^{-4} \mathrm{M}$ \\
\hline $\mathrm{CO}(\text { EINA })_{2}$ & $\begin{array}{c}38.20 \\
(38.10)\end{array}$ & $\begin{array}{c}4.77 \\
(4.88)\end{array}$ & $\begin{array}{c}7.42 \\
(7.50)\end{array}$ & $\begin{array}{c}15.64 \\
(15.17)\end{array}$ & 2.91 & 0.030 & $1.1 \times 10^{-5} \mathrm{M}$ \\
\hline $\mathrm{Ni}(\text { EINA) })_{2}$ & $\begin{array}{c}38.22 \\
(38.30)\end{array}$ & $\begin{array}{c}4.77 \\
(4.85)\end{array}$ & $\begin{array}{c}7.43 \\
(7.5 \mathrm{O})\end{array}$ & $\begin{array}{c}15.58 \\
(15.61)\end{array}$ & 2.34 & 0.535 & $6.1 \times 10^{-4} \mathrm{M}$ \\
\hline
\end{tabular}

Table-2:

\begin{tabular}{|c|c|c|c|c|}
\hline Assignments & HEINA & $\mathrm{Ni}(\text { EINA })_{2}$ & $\mathrm{CO}(\mathrm{EINA})_{2}$ & $\mathrm{Cu}(\mathrm{EINA})_{2}$ \\
\hline $\mathrm{OH}$ & 3400 & 3400 & 3200 & 3200 \\
\hline Ester $\mathrm{C}=\mathrm{O}$ & 1760 & 2142 & 2420 & 2390 \\
\hline Ketone $\mathrm{C}=\mathrm{O}$ & 1745 & ---- & ---- & 1740 \\
\hline $\mathrm{C}=\mathrm{N}$ & 1640 & 1605 & 1600 & 1610 \\
\hline $\mathrm{CH}_{3}$ & $\begin{array}{l}1458 \\
1378\end{array}$ & $\begin{array}{l}1410 \\
1390\end{array}$ & $\begin{array}{l}1410 \\
1380\end{array}$ & $\begin{array}{l}1440 \\
1388\end{array}$ \\
\hline $\mathrm{COOC}_{2} \mathrm{H}_{5}$ & $\begin{array}{l}1268 \\
1078 \\
\end{array}$ & $\begin{array}{l}1300 \\
1135\end{array}$ & $\begin{array}{l}1310 \\
1090\end{array}$ & ---- \\
\hline $\mathrm{N}-\mathrm{O}$ & 970 & 965 & 960 & 965 \\
\hline
\end{tabular}

\section{References}

[1]. Venkateswar R P, Ashwini K and Ammani S, bull. Soc. Ethiop., 21(1), (2007) 63-73.

[2]. Ranfard J D, Sadler P J and Tocher D A, J Chem Soc Dalton Trans; 22, (1993) 3393-3399.

[3]. Natrajan C and Hussain A N, Ind J Chem, 22 A, ( 1983) 527.

[4]. Thakkar N V and Halder B C J Inorg. Nucl. Chem., 42, (1980) 843.

[5]. Natrajan C and Hussain A N, Ind J Chem, 20 A, (1981) 307.

[6]. Talwar U B and Halder B C, J Inorg Nucl Chem, 32, (1970) 213.

[7]. Prakash D, Singh, B P and Gupta O P, Vijnana Parishad, Anusandhan Patrika, 35(4), (1992) 305.

[8]. Banerjee A K, Layten A J, Nyholm R S and Truter M R, J. Chem Soc, 292 A, (1970)18 - 84,.

[9]. Banerjee A K, Prakash D and Roy S K, J Ind Chem Soc, 53, (1976) 773.

[10]. Prakash D, Gupta A K and Kumari S Asian J Chem, 15(2), (2003) 860.

[11]. Palm A and Werbin A Con J Chem, 32, (1954) 858. 